\title{
A FABRICATION OF 4H-SILICON CARBIDE BASED- LATERAL SCR FOR ESD PROTECTION DEVICE
}

\author{
Kyoung-Il Do ${ }^{1}$ and Tae-Ryong Park ${ }^{2 *}$ \\ ${ }^{1}$ Department of Electronics \& Electrical Engineering, Dankook University, Korea \\ ${ }^{2}$ Department of Computer Engineering, Seokyeong University, Korea \\ ${ }^{1}$ kido888@naver.com, ${ }^{2}$ trpark@skuniv.ac.kr
}

\begin{abstract}
This paper demonstrates a silicon carbide-based lateral silicon controlled rectifier (SCR) for use as an electrostatic discharge (ESD) protection device for high current ICs mounted on EVs or self-driving vehicles. The protection devices were designed with three split items and were fabricated with a line width of $0.5 \mu \mathrm{m}$. The protection devices were verified in terms of their electrical characteristics by using a transmission line pulse (TLP) system and a curve tracer. The measurements indicate that the devices have a trigger voltage of $165 \mathrm{~V}$ and a holding voltage of $40 \mathrm{~V}$. The lateral SCR devices have a breakdown voltage (BV) of $82 \mathrm{~V}$. In addition, the second breakdown current of the demonstrated SCR is above $18 \mathrm{~A}$.
\end{abstract}

Keywords - electrostatic discharge (ESD) silicon carbide (SiC), silicon-controlled rectifier (SCR)

\section{INTRODUCTION}

For the last few years, the advantages of using power devices based on gallium nitride $(\mathrm{GaN})$ and silicon carbide ( $\mathrm{SiC})$ technologies have been well discussed [1],[2]. In particular, $\mathrm{SiC}$ devices have been considered to have superior characteristics to Si-based devices due to their high voltage operation, high power, high frequency, and high temperature operation endurance [3]-[5]. Therefore, researches on $\mathrm{SiC}$ power semiconductors have been continuously carried out to overcome the limitations of $\mathrm{Si}$ power semiconductors. Recently, in the EV industry, research is being conducted to develop a SiC power semiconductor, such as developing a high-performance inverter that connects an electric motor and a battery[6]. They are a very important component of the EV industry. Therefore, the $4 \mathrm{H}-\mathrm{SiC}$-based ESD protection circuit needs to be studied to improve the reliability of $\mathrm{SiC}-\mathrm{IC}$ [7]. The main research on $\mathrm{SiC}$ has focused on developing devices with a vertical structure device because there large current driving capability, which is beneficial for use in high power systems. However, a lateral structure device may be more appropriate for integration depending on the given application. Meanwhile, lateral-SCRs, which are known as thyristors, are devices that are extensively used in power device applications because these can switch from a very high impedance state to a very low impedance state. For the same reason a properly designed SCR can also be a very efficient ESD protection circuit [8],[9]. However, silicon carbide-based SCR has not yet been developed for use as an ESD protection device.

In this paper, It demonstrate a silicon carbide-based SCR device that was developed for use in an ESD protection circuit. Its suitability for use in ICs was demonstrated, and

Received: March 25, 2019

Reviewed: April 29, 2019

Accepted: May 3, 2019

* Corresponding Author

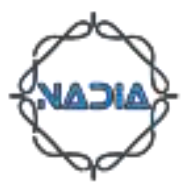


sample devices were fabricated with a minimum line width using a $0.5 \mu \mathrm{m}$ process.

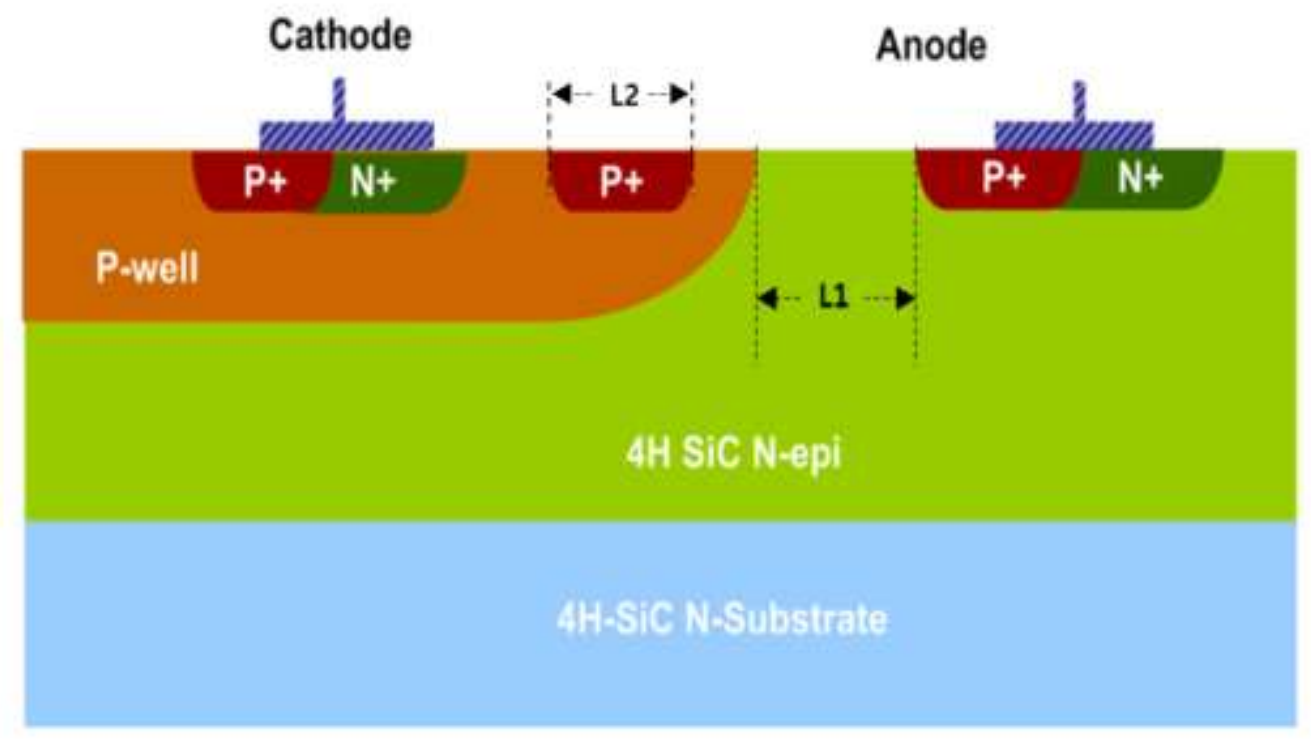

Fig. 1 Cross-sectional View of the Silicon Carbide Lateral SCR

\section{DEVUCE FABRUCATION AND DESCRIPTION}

Figure 1 shows a cross-sectional view of the $4 \mathrm{H}-\mathrm{SiC}$ lateral SCR, and it essentially consists of a PNPN structure. The P+ region in the N-epi forms the anode of the SCR where holes are injected into the $\mathrm{N}$-epi. The $\mathrm{N}+$ region in the $\mathrm{P}$-well forms the cathode of the SCR from which electrons are injected into the P-well. The connection to the $\mathrm{N}$-epi is made through an $\mathrm{N}+$ contact in the $\mathrm{N}$-epi, while the $\mathrm{P}+$ contact in the well is the connection to the p-well. The thickness and doping concentration of the P+ layer is 0.2 $\mu \mathrm{m}$ and $1 \times 10^{15} \mathrm{~cm}^{-3}$ approximately. The thickness and doping of the p-well layer are 0.7 $\mu \mathrm{m}$ and $1 \times 10^{12} \mathrm{~cm}^{-3}$. The process step of $\mathrm{N}+$ implant and $\mathrm{P}+$ implant were carried out at $650{ }^{\circ} \mathrm{C}$ by using a nitrogen and aluminum source, respectively. Also, the P-well step was carried out at $650^{\circ} \mathrm{C}$ using an aluminum source. The properties of the device are also summarized in Table I. Figure 2 shows layout with design variables and (b) magnified image of the silicon carbide lateral SCR. The design parameters L1 and L2 are designed to optimize the electrical characteristics of the silicon carbide lateral SCR. L1 is the distance between the $\mathrm{P}$-well region and the $\mathrm{P}+$ region, and L2 is the length of the additionally formed $\mathrm{P}+$ floating region in the $\mathrm{P}$-well.

Table I. Summary of Doping Concentration and Depth of Layer

\begin{tabular}{|c|c|c|}
\hline Layer & $\begin{array}{c}\text { Junction } \\
\text { Depth }\end{array}$ & $\begin{array}{c}\text { Doping } \\
\text { concentration }\end{array}$ \\
\hline N+ Implant & $0.2 \mu \mathrm{m}$ & $9 \times 10^{14} \mathrm{~cm}^{-3}$ \\
\hline P+ Implant & $0.2 \mu \mathrm{m}$ & $1 \times 10^{15} \mathrm{~cm}^{-3}$ \\
\hline P-well Implant & $0.7 \mu \mathrm{m}$ & $2 \times 10^{14} \mathrm{~cm}^{-3}$ \\
\hline
\end{tabular}




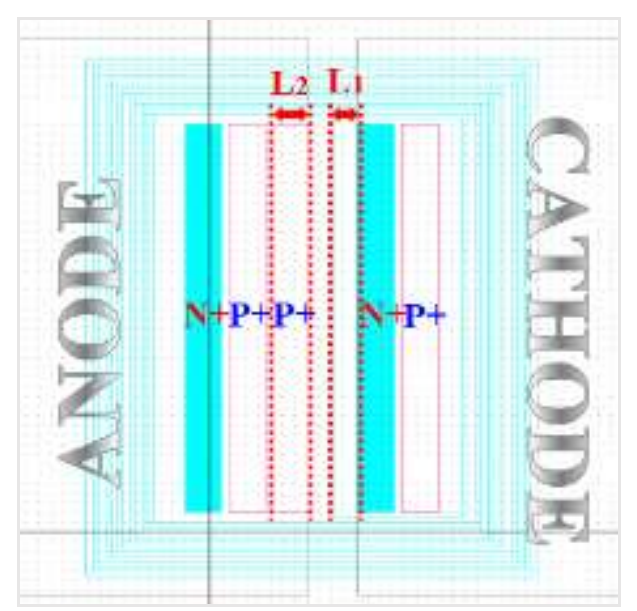

(a)

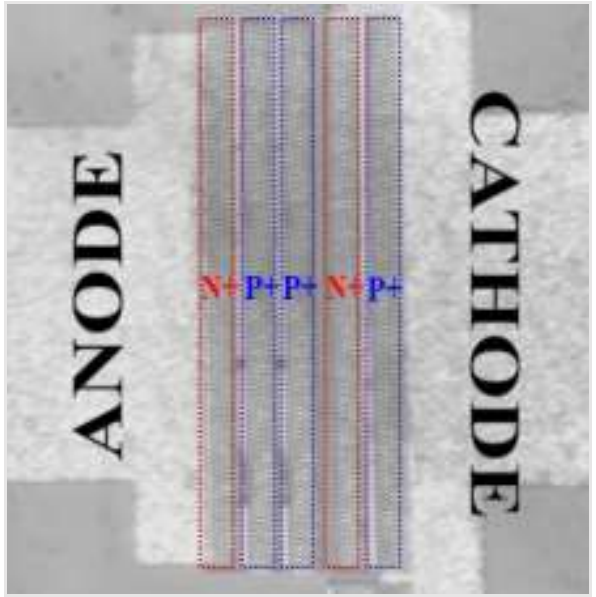

(b)

Fig. 2 (a) Layout with Design Variables and (b) Magnified Image of the Silicon Carbide Lateral SCR.

\section{METHODOLOGY AND EXPERIMENTAL RESULTS}

\subsection{METHODOLOGY}

The operation principle of this silicon carbide-based lateral SCR device is as follows. When ESD surge is applied to the anode stage, the potential of the N-epi layer increases. After the potential reaches the critical point, an avalanche breakdown occurs between the P-wells. Electron-hole pairs(EHP) are generated and EHP move in the direction of P-well and N-epi, respectively, to increase the potential. As a result, the diode is turned on and the two parasitic NPN / PNP bipolar transistors operate with each other supplying the base current.

\subsection{TLP MEASUREMENT}

The results of the TLP measurements of the 4H-SiC lateral SCR and TLP characteristics with design variable L1 shown in Figure 3. L1 is (a) $10 \mu \mathrm{m}$, (b) $15 \mu \mathrm{m}$ and (c) $20 \mu \mathrm{m}$, respectively [10]. L1 was set as a design parameter to verify the trigger voltage characteristics of the device. The L1 design variable increases up to $10 \mu \mathrm{m}, 15$ $\mu \mathrm{m}$ and $20 \mu \mathrm{m}$, and the trigger voltage increases from $165 \mathrm{~V}$ to $227 \mathrm{~V}$, respectively. The $\mathrm{L} 1$ design variable represents the distance between the $\mathrm{P}+$ region of the anode terminal and the $\mathrm{P}$-well. A greater increase in distance from the $\mathrm{P}+$ of the anode side region to the $\mathrm{P}$-well results in an increase in the base region of the parasitic PNP transistor. Therefore, the width of the space charge region increases to the direction of the $\mathrm{N}$-well, and then the maximum electric field where the avalanche breakdown occurs is reduced, which in turn causes an increase in the breakdown voltage. A formula between the depletion layer and the maximum electric field is shown as follows [11], In this case, the design variable L2 has a length of $0 \mathrm{um}$.

$$
E_{\max }=\frac{-2\left(V_{b i}+V_{R}\right)}{W}
$$




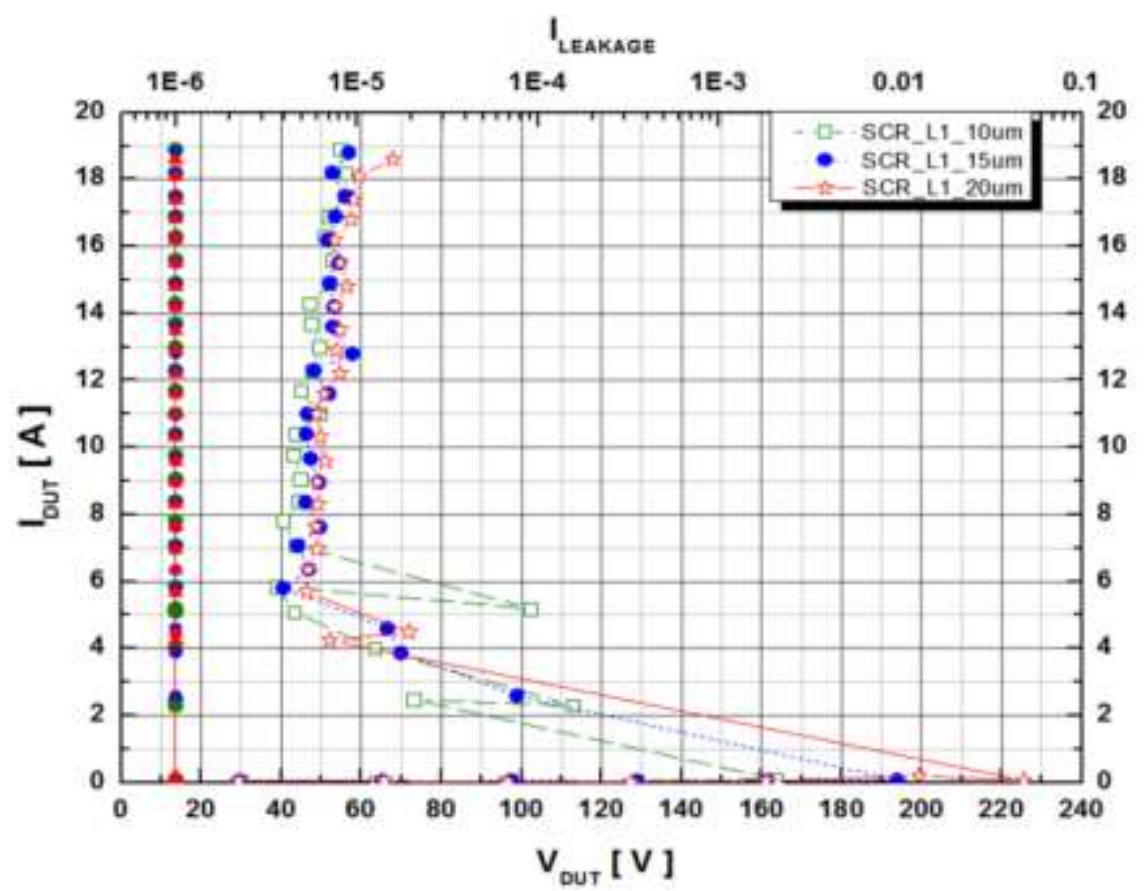

(a)

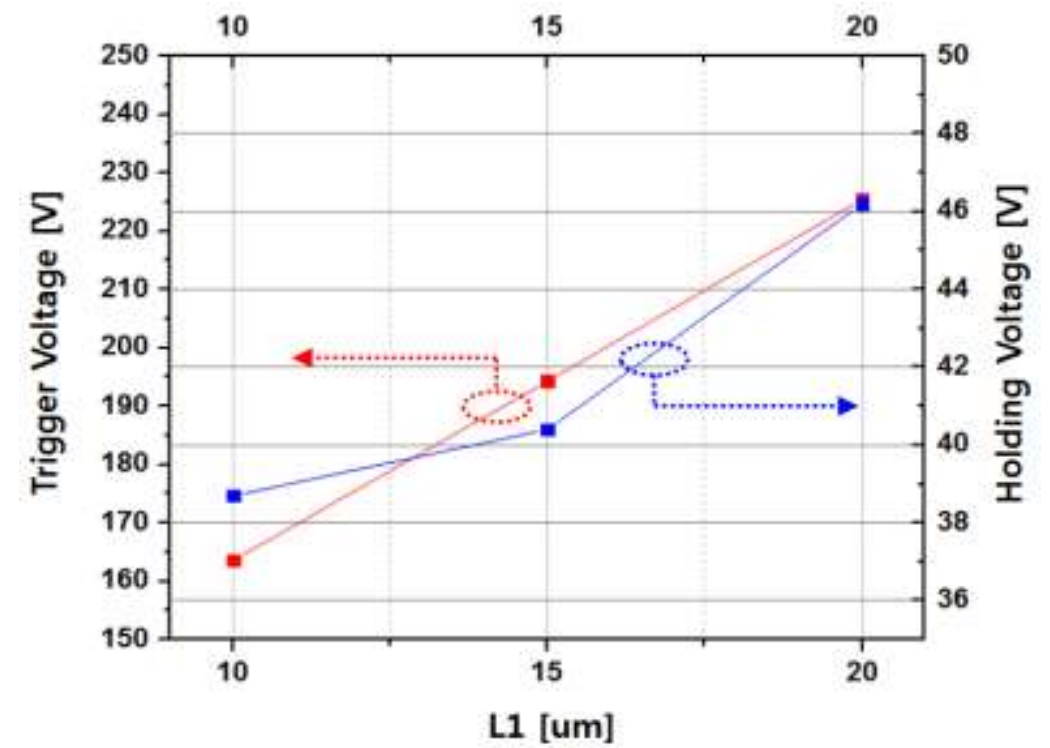

(b)

Fig. 3 TLP measurement results for the 4H-SiC lateral SCR (a) TLP characteristic and Trigger voltage and Holding voltage

Where $\mathrm{V}_{\mathrm{bi}}$ indicates the potential barrier, $\mathrm{V}_{\mathrm{R}}$ is the applied reverse bias, and $\mathrm{W}$ is a width of the space charge region. Assuming that the applied reverse bias is constant, the more the width of the space charge region increases, the less $\mathrm{E}_{\max }$ becomes. Therefore, the breakdown voltage increases with $\mathrm{L} 1$, which raises the trigger voltage of the device. In addition, the current driving capability of the device has a high current driving characteristic greater than $18 \mathrm{~A}$. 


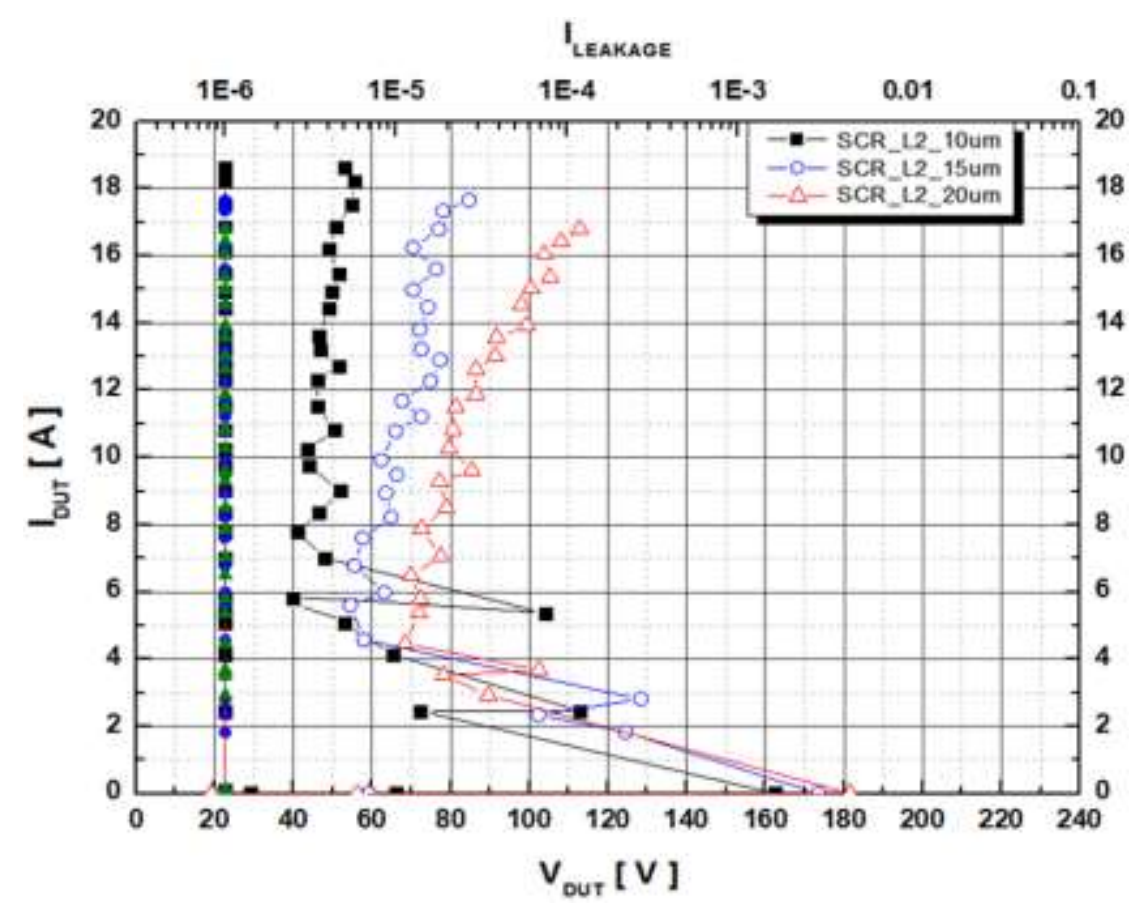

(a)

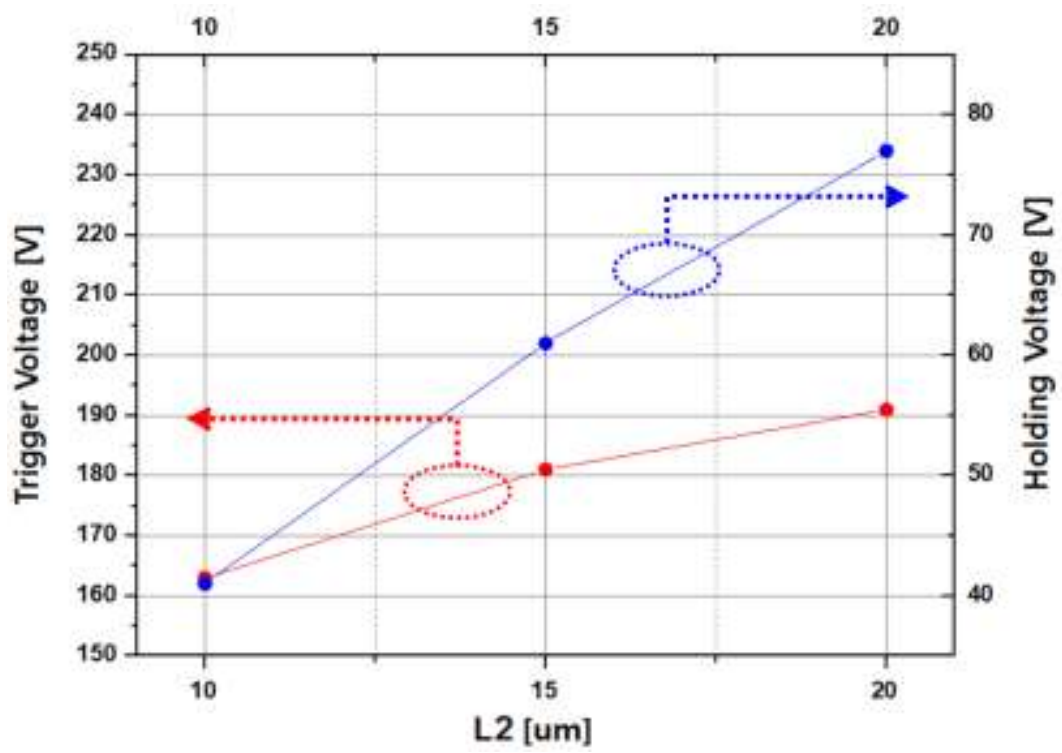

(b)

Fig. 4 TLP measurement results for the 4H-SiC lateral SCR (a) TLP characteristic and (b) Trigger voltage and Holding voltage

On the other hand, L2 added to the $\mathrm{P}$-well region is the length of the $\mathrm{P}+$ floating region. Unlike L1, L2 is the effective base region of the NPN parasitic bipolar transistor. As the length of L2 increases, more electrons are recombined in the base region of the NPN parasitic bipolar transistor. Therefore, the holding voltage of the silicon carbide lateral SCR is increased because it increases the emitter injection efficiency of the NPN parasitic bipolar transistor [12]. Also, when compared to L1, L2 is a P + implant region and has a higher doping concentration. As a result, a higher holding voltage can be achieved. However, the addition of an implant region can cause the current to flow to the substrate surface, which may affect the degradation of It2. According to the measurement results, the holding voltage increases by about $41 \mathrm{~V}-61 \mathrm{~V}-77 \mathrm{~V}$ and the trigger voltage 
increases by about $163 \mathrm{~V}-181 \mathrm{~V}-191 \mathrm{~V}$. Figure 4 shows the change of electrical characteristics of the silicon carbide lateral SCR with the change of L2, and the design variable L1 is fixed at 10um. Table II summarizes the electrical characteristic according to changes in variation factors. Therefore, the L2 variation of the design parameter is suitable for increasing the holding voltage.

Table II. The electrical characteristic according to changes in variation factors

\begin{tabular}{|c|c|c|c|c|}
\hline \multicolumn{2}{|c|}{ Variation } & $\begin{array}{c}\text { Holding } \\
\text { Voltage[V] }\end{array}$ & $\begin{array}{c}\text { Holding } \\
\text { Current[A] }\end{array}$ & $\begin{array}{c}\text { Second Breakdown } \\
\text { Current[A] }\end{array}$ \\
\hline \multirow{2}{*}{$\begin{array}{c}\text { L1 } \\
\text { (L2= } \\
\text { Oum })\end{array}$} & 10um & 38.8 & 5.85 & 18.9 \\
\cline { 2 - 5 } & 15um & 40.5 & 5.8 & 18.7 \\
\hline \multirow{2}{*}{$\begin{array}{c}\text { L2 } \\
\text { (L1= }\end{array}$} & 10um & 45.8 & 5.72 & 18.5 \\
\cline { 2 - 5 } 10um $)$ & 15um & 61.1 & 5.9 & 18.8 \\
\cline { 2 - 5 } & $20 \mathrm{um}$ & 77.2 & 5.8 & 16.9 \\
\hline
\end{tabular}

\subsection{THERMAL RELIABILITY}

High temperature measurement tests are very important because they affect the electrical characteristics of ESD protection circuits [13]. The silicon carbide material is known to have excellent temperature characteristics. ESD damage is caused by thermal damage, which can be a very significant advantage in ESD mode. Damage caused by joule-heating can deteriorate the holding voltage, the holding current, and the performance of It2. First, as the temperature increases, the carrier mobility decreases. Thus, the base-emitter voltage (VBE) of the parasitic NPN / PNP BJT decreases and the holding voltage decrease. And due to the decrease of the mobility, the resistance of the well and the substrate increases and the holding current decreases. An increase in resistance also means a decrease in Ron and It2. In the thermal reliability test, the TLP system is used for the measurement, while the wafer is heated by a hot chuck system and a controller. In the case of the below equations (2) - (4), the voltage drop, current, current gain $(\beta)$, and resistances of the parasitic bipolar regions and the well region formed in the device are expressed.

$$
\begin{gathered}
V_{h}=V_{E B Q 1}+V_{B C Q 1}+V_{E B Q 2} \\
V_{h}=V_{B E o n}+V_{B C Q 1} \\
I_{h}=\frac{V_{B E O n}}{\beta_{N P N} \beta_{P N P^{-1}}}\left[\frac{1}{R_{n}}\left(\beta_{P N P}+1\right) \beta_{N P N}+\frac{1}{R_{p}}\left(\beta_{N P N}+1\right) \beta_{P N P}\right.
\end{gathered}
$$

Figure 5 shows the thermal reliability $(300-500 \mathrm{~K})$ measurement results of the ESD protection circuit. It shows the electrical characteristics of the conventional type (holding current, holding voltage, secondary breakdown current, on-resistance). Typically, since the carrier mobility decreases as the temperature increases, the resistance value of the 
well region and the epitaxial region is increased and consequently the holding voltage is lowered. Whereas, while increasing from $300 \mathrm{~K}$ to $500 \mathrm{~K}$, the secondary breakdown current is not lowered and hardly changes due to thermal damage. Similarly, the heat loss rate of the holding voltage and the holding current is very low. Thus, the data demonstrate good high temperature properties and thermal reliability. Figure 6 shows the results of the thermal reliability measurement $(300-500 \mathrm{~K})$ for the variation types L1 and L2 for the holding voltage. The design variable can be further influenced by the mobility reduction due to the temperature increase by directly increasing the $\mathrm{L}$ of the device. However, according to the measurement results, the proposed SIC-based device has almost no decrease in holding voltage while all the devices are changing from $300 \mathrm{~K}$ to $500 \mathrm{~K}$. Therefore, it can be seen that the electrical characteristics optimization due to the design variables L1 and L2 also have excellent high-temperature reliability.

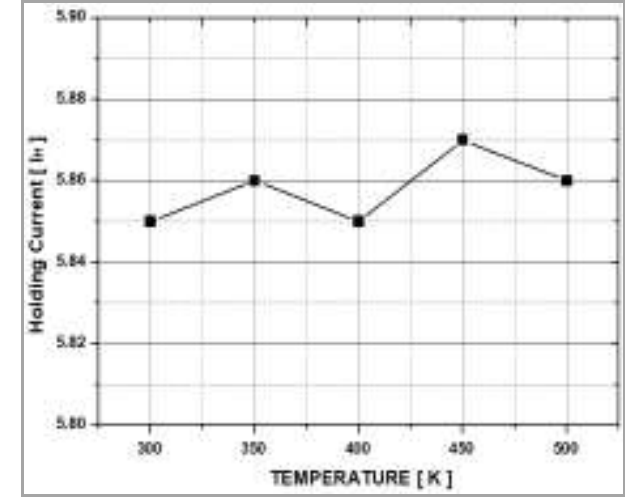

(a)

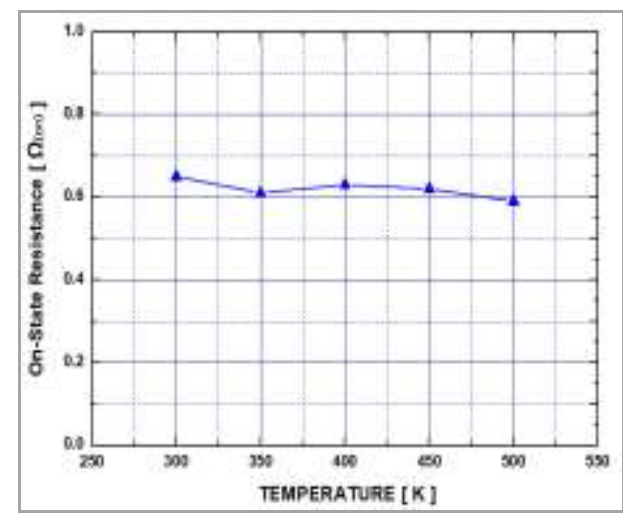

(c)

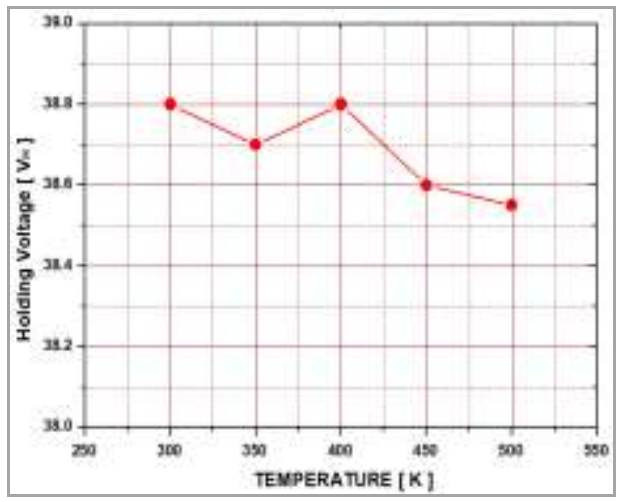

(b)

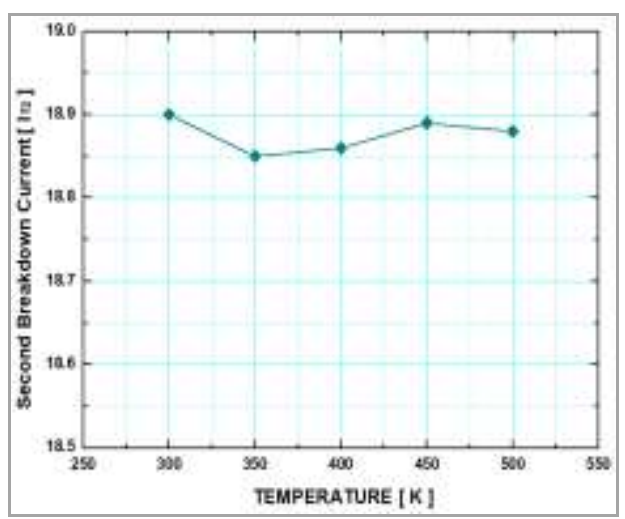

(d)

Fig. 5 The high temperature (300-500 K) characteristics for the 4H-SiC Lateral SCR (a) Holding current, (b) Holding voltage, (c) On-resistance and (d) Second breakdown current. 


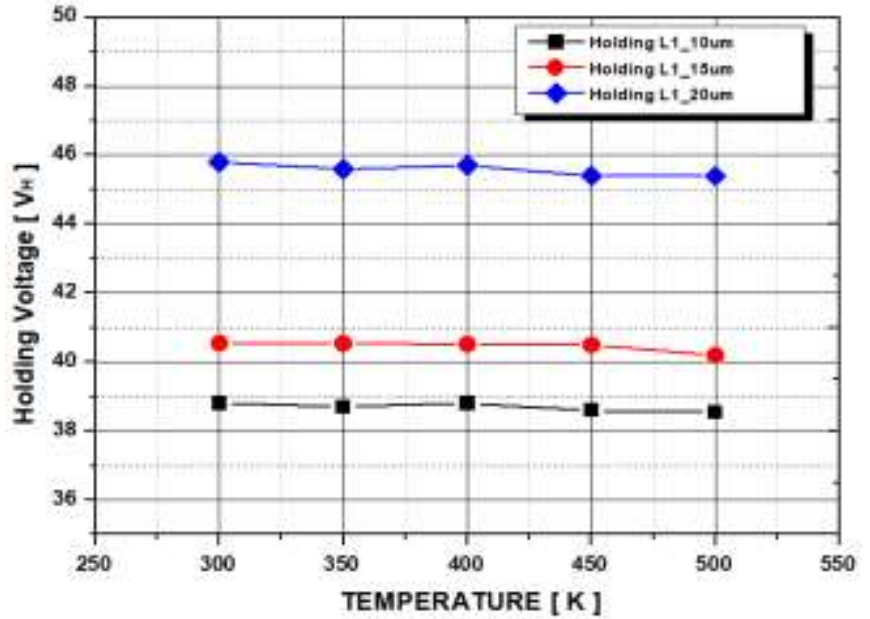

(a)

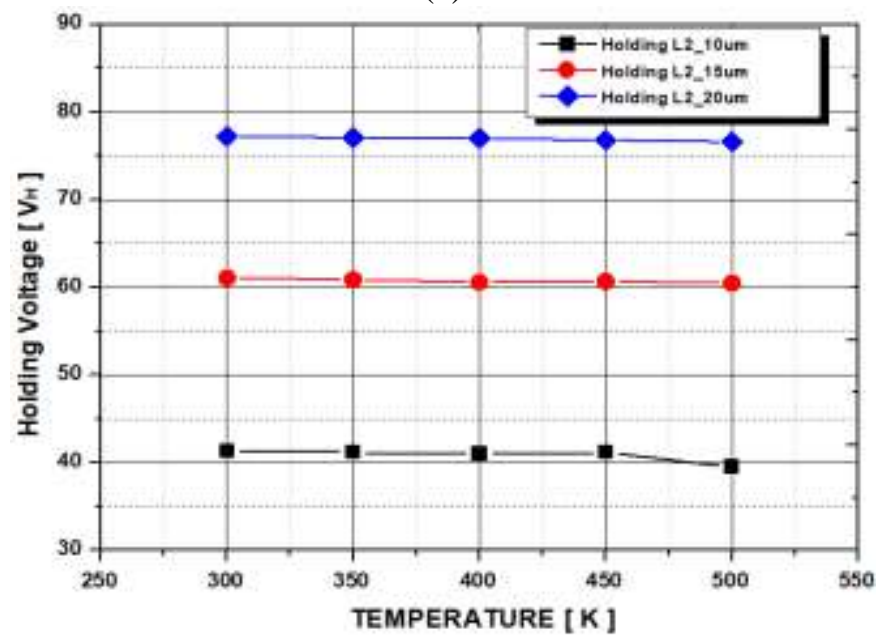

(b)

Fig. 6 Temperature (300-500 K) characteristics according to changes in variation factors (a) L1 and (b) L2

\subsection{BREAKDOWN VOLTAGE AND HBM, MM TEST}

It performed DC measurements to determine the leakage current and DC breakdown voltage of the SCR device. Figure 7 shows the DC breakdown voltage and the leakage current of the $4 \mathrm{H}-\mathrm{SiC}$ SCR device. The results indicate that the $4 \mathrm{H}-\mathrm{SiC}$ lateral SCR has a breakdown voltage of $82 \mathrm{~V}$. Although the I-V characteristics obtained by the TLP measurement are said to be converted to HBM and MM values, there might be deviation between the results of the TLP measurements and those of the HBM and MM. Therefore, a measurement that imposes a current for the protection device by realizing an actual ESD current should be accompanied. It measured the HBM and MM to verify the robustness of the SCR device. The SCR device was proven to have an ESD robustness of HBM $8 \mathrm{kV}$ and MM $800 \mathrm{~V}$, which means that these have a higher fault tolerance characteristic that exceeds the HBM $2 \mathrm{kV}$ and MM $200 \mathrm{~V}$ of CMOS technologies. 


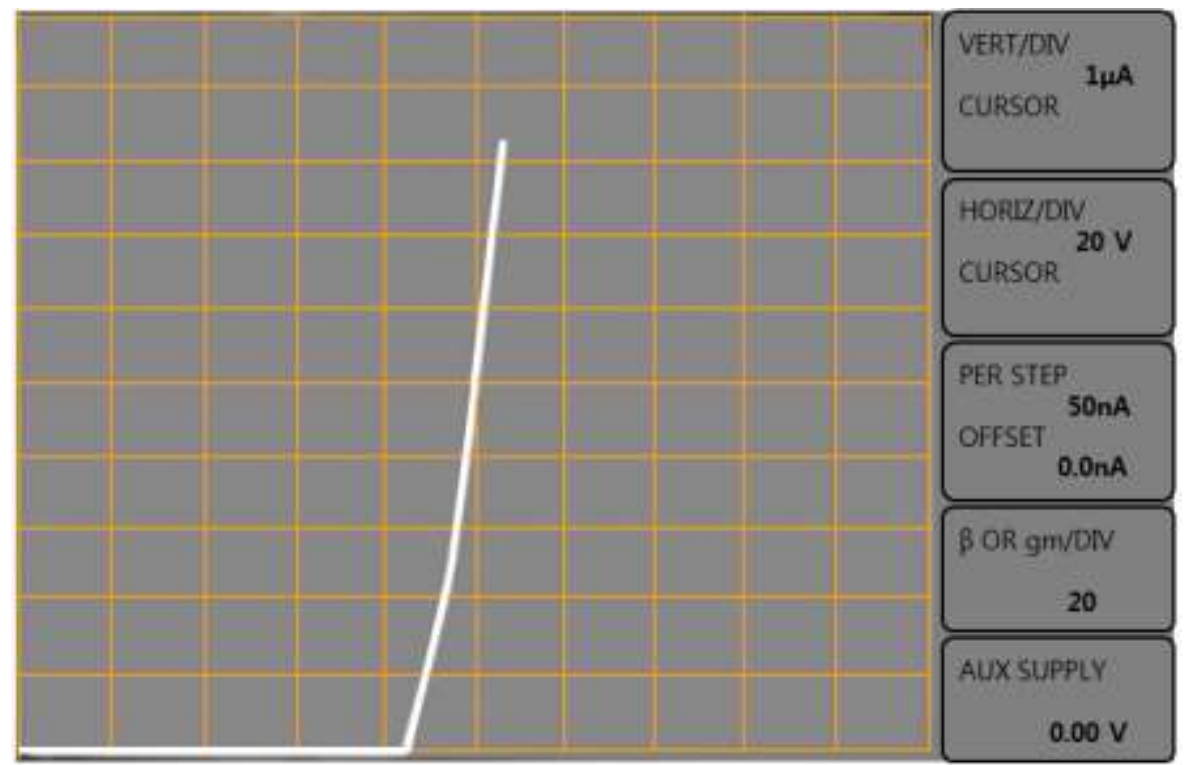

Fig. 7 Breakdown Voltage Characteristics of the 4H-SiC lateral SCR

\section{CONCLUSIONS}

This paper presented a $4 \mathrm{H}-\mathrm{SiC}$ lateral SCR for use as an ESD protection device. The SCR device was fabricated with a line width of $0.5 \mu \mathrm{m}$ process. To verify the electrical characteristics, the TLP system is used for the measurement, while the wafer is heated by a hot chuck system and a controller. The design variations are the length of the epi area and the length of the added implant area. The results indicate that when the L1 distance of $20 \mu \mathrm{m}$ between the $\mathrm{p}+$ of the anode terminal and the $\mathrm{p}$-well, the device has a trigger voltage of $227 \mathrm{~V}$ and a holding voltage of $45.8 \mathrm{~V}$. When the L2 length of the added P + implant region is $20 \mu \mathrm{m}$, the device has a trigger voltage of $181 \mathrm{~V}$ and a holding voltage of $77.2 \mathrm{~V}$. Also, the device was proven to have a high current driving capability above 18 A and passed HBM $8 \mathrm{kV}$ and MM800 V. SiC-based devices show that as temperature increases, electrical properties due to mobility are hardly changed. Therefore, by adjusting L1 and L2 to optimize the trigger voltage and holding voltage, which is the most critical electrical characteristic, ESD protection circuit is expected to contribute to the reliability of ICs mounted on EVs or self-driving vehicles Due to its excellent material properties.

\section{ACKNOWLEDGEMENTS}

This research was supported by Seokyeong University in 2016.

\section{REFERENCES}

[1] Ashok Bindra, "Wide-Bandgap-Based Power Devices," IEEE Power Electronics Magazine, (2015), pp. 42-47.

[2] Jin Wei, Huaping Jiang, Qimeng Jiang, and Kevin J. Chen, "Proposal of a GaN/SiC Hybrid Field-Effect Transistor for Power Switching Applications,” IEEE Trans. Electron Device., vol.63, no.6, (2016), pp. 2469-2473.

[3] Masaru Nagao, Masaki Ajioka, and Fumiaki Kawai, "SiC-Emerging Power Device Technology for Next-Generation Electrically Powered Environmentally Friendly Vehicles" IEEE Electr. Devices vol. 62, no. 2, (2005), pp. 278 - 285.

[4] S. Ji, Z. Zhang, and F. Wang, "Overview of high voltage sic power semiconductor devices: development and application,” CES Trans. Electr. Mach. Syst., vol. 1, no. 3, (2017), pp. 254-264.

[5] Qingwen Song, Shuai Yang, Guannan Tang, Chao Han, Yimeng Zhang, Xiaoyan Tang, Yimen Zhang, “4H-SiC Trench MOSFET with L-Shaped Gate," IEEE Electr. Device Lett., vol. 37, no. 4, (2016), pp. 463-466. 
[6] Diksha S. Ramteke, Manisha B. Gaikwad, "Isolated DC-DC Converter Fed DC Motor for Bidirectional Electric Vehicular Application” International Conference on Smart Electric Drives \& Power, (2018), pp. 33-37.

[7] Kyoung-Il Do, Byung-Seok Lee, and Yong-Seo Koo, "Study on 4H-SiC GGNMOS Based ESD Protection Circuit with Low Trigger Voltage Using Gate-Body Floating Technique for 70-V Applications" IEEE Electron Device Lett., vol. 40, no. 2, (2019), pp. 283-286.

[8] Shen-Li Chen, Yu-Ting Huang, Chih-Ying Yen, Kuei-Jyun Chen, Yi-Cih Wu, Jia-Ming Lin, ChihHung Yang, "ESD Protection Design for the 45-V pLDMOS-SCR (p-n-p-Arranged) Devices with Source-Discrete Distributions" IEEE Global Conference on Consumer Electronics (2018), pp. 1-2.

[9] C. W. Chan, F. Li, A. Sanchez, P. A. Mawby, and P. M. Gammon, "Comparative Study of RESURF $\mathrm{Si} / \mathrm{SiC}$ LDMOSFETs for High-Temperature Applications Using TCAD Modeling," IEEE Electron devices vol.64 no.9 (2017), pp. 3713-3718.

[10] Donald A. Neamen, "Semiconductor Physics and Device: basic principle, $3^{\text {rd }}$ ed., (2003). pp. 691-701.

[11] B. B. Song and Y. S. Koo, "Low Ron and high robustness ESD protection design for low-voltage power clamp application," Electron. Letter, vol. 52, no. 18, (2016), pp. 1554-1555.

[12] Bo-Bae Song, Kyoung-Il Do, And Yong-Seo Koo, "SCR-Based ESD Protection Using a Penta-Well for 5 V Applications,” IEEE Electron Device Society, vol.6, (2018), pp. 691-695. 